\title{
An Empirical Study of English Pragmatic Failure of Chinese Non-English Majors
}

\author{
Haigang Li \\ Zhengzhou Institute of Aeronautical Industry Management, Zhengzhou, China \\ Email: hg1018@126.com
}

\begin{abstract}
This paper analyzes the phenomena of pragmatic failure committed by non-English-major college students in intercultural communication from pragmatics perspective, and discusses the manifestations of pragmatic failure in real communication. After getting a better understanding of the phenomena of pragmatic failure, some suggestions are made on how to raise the pragmatic awareness, and foster the pragmatic competence of non-English majors.
\end{abstract}

Index Terms - pragmatic failure, pragmatic competence, linguistic competence

\section{INTRODUCTION}

As mankind's communication tool and information carrier, language, like the air we breathe, is something which the society and its members cannot do without, not even for a short period of time. English, as an international language, is the most widely used all over the world. As a result, it is absolutely vital for many Chinese learners to have a good command of English. However, although many Chinese learners have little difficulty understanding the literal meaning of target language in authentic communication situations, they may not interpret the utterances correctly, or express themselves appropriately. Intercultural communication sometimes breaks down in real situations, not because of the non-native speaker's errors in grammar, or their inaccurate pronunciation in the target language, but because of their pragmatic incompetence, which leads to pragmatic failure. In other words, they may be incapable of using target language effectively in intercultural communication.

Pragmatic failure, which is first proposed by Thomas (1983), refers to the inability to understand what is meant by what is said. She points out that interference in communication is generally referred to as pragmatic failure, which has nothing to do with grammatical mistakes but comes from inappropriate ways of speaking or the unconventional expressions resulting from different perceptions of what is considered as appropriate linguistic behaviors (Thomas, 1983). He (1988) defines it as "failure to achieve the desired communication effect in communication". He proposes that pragmatic failure is not the general performance errors in using words or making sentences, but those mistakes which fail to fulfill communication because of infelicitous style, incompatible expressions and improper habit (He, 1988). Pragmatic failure belongs to the field of cross-cultural pragmatics, a new branch of pragmatics which has been developed rapidly in the past two decades. Several main studies about pragmatic failure have been conducted at home (Huang, 1984; He \& Yan, 1986; Wang, 1990; Hong, 1991; Gu, 2003; Li, 2005) and abroad (Thomas, 1983; Wolfson, 1983; Leech, 1983), but few have been done on Chinese Learners of English, especially non-English majors.

With the advancement of society and economy, communication among people from different countries is more frequent and important, which makes a claim for higher requirement for English learners' pragmatic competence. In 2007, Chinese College English Curriculum Requirements for non-English majors clearly states that the ability of students' comprehensive language application should be trained. However, the fact is often that college graduates' pragmatic competence can hardly be expected to meet the needs of practical work. Therefore, we should not only find the reasons theoretically but also deal with it in actual practice.

Through questionnaire survey, this paper attempts to analyze the phenomena of pragmatic failure committed by non-English majors and discuss the manifestations of pragmatic failure in real communication. And then, some suggestions are made on how to avoid pragmatic failure and foster the pragmatic competence of non-English majors.

\section{EMPIRICAL STUDY}

\section{A. Research Purpose}

So far, many studies which have been made on pragmatic failure mostly aims at college students of English major or research into the inspiration of English teaching in general. Few studies have been carried out on Chinese non-English majors. Therefore, author attempts to investigate the pragmatic failure of Chinese non-English-major college students. Then the paper tries to come up with some countermeasures to improve the method of English teaching, which may benefit the avoidance of college students' pragmatic failure and the improvement of their pragmatic competence. In order to get a clear knowledge of pragmatic competence of non-English majors, and take appropriate instructional strategies, a survey is carried out with questionnaires in some college students of non-English majors from Zhengzhou 
Institute of Aeronautical Industry Management (hereinafter called ZZIA). These can be illustrated by the research questions as follows:

1) After acquiring the knowledge of language system, will Chinese non-English-major college students are able to naturally use language?

2) Will Chinese non-English majors with good grammatical competence necessarily develop their pragmatic competence in English?

3) In what aspects pragmatic failure will occur as far as Chinese non-English majors are concerned?

\section{B. Subjects \& Instruments}

The subjects in the research are 220 freshmen and 188 sophomores of non-English majors in ZZIA. Although they cannot represent all the non-English majors in China, the test results can offer some inspirations for further researches. 220 freshmen are non-English-major learners who mainly study liberal arts, such as, Chinese and literature, philosophy and economics, law, history, etc. It is generally assumed that students who major at liberal arts have a better command of linguistic competence because they are much more sensitive to language. Whereas 188 sophomores are non-English majors who passed CET-4 (College English Test Band-Four). They should have certain linguistic competence. Freshmen and sophomores are chosen in the study because they are needed to confirm the conclusion, which is proposed by Bardovi-Harlig (1999), that high levels of grammatical competence do not guarantee concomitant high levels of pragmatic competence.

The instruments employed in this study are questionnaires, which are designed on the basis of He's (1988) "English Pragmatic Competence Investigation" attached to "A Survey of Pragmatics" and He \& Yan's (1986) "The Pragmatic Failures of Chinese Students in Communication in English — An Investigation of Chinese-English Pragmatic Difference". The content involves some common pragmatic phenomena in our daily lives, which included rejection, request, invitation, apology, praise, acknowledgement, greeting, etc.

\section{Procedure of the Study}

Methods of this study are conducted by using an anonymous questionnaire with random sampling and literature analysis. The questionnaire covers two parts: the fist part includes some personal information, such as grade, gender and the range of average score of regular quizzes, midterm exams, final exams, etc. The second part goes to the questionnaire to which subjects are required to respond according to the situation given. In order to improve the accuracy of statistical analysis, each item of questionnaire is followed by scales of confidence investigation through which mental attitudes of subjects can be clearly observed when choices are made.

408 subjects from ZZIA aged from 18 to 21 are asked to respond to some items of refusal, instruction, acknowledgement, praise, request, greeting, apology, etc. in the questionnaire. Before the questionnaires are distributed to the subjects, it is made clear to them that the purpose is to test their pragmatic competence and get the valuable data about current situation of their pragmatic failure. They have to finish the questionnaire individually. The answer sheets of questionnaires are collected soon after the subjects finish responding to them in order to keep them from discussing and altering their choices. All the subjects have to hand in the questionnaires. All items in the questionnaires should be responded to. Otherwise, such questionnaires will be excluded from this research. All questionnaires should be valid.

The study has roughly gone through three periods: First, the investigation about English pragmatic competence and pragmatic failure, which started in September, 2010 and ended in October, 2010. Second, the collection of reference materials and statistical analysis about pragmatic failure from the testing results from October, 2010 to November, 2010. Third, attempt to illustrate some inspirations on how to avoid pragmatic failure based on the statistical analysis about the research findings from November, 2010 to March, 2011.

\section{RESULTS AND DISCUSSION}

\section{A. Contrastive Analysis of Pragmatic Competence between Freshmen and Sophomores}

During research, 408 pieces of questionnaire are handed out among freshmen and sophomores with 395 pieces handed in which accounted for 96.8\%. Through random sampling, 360 pieces of questionnaire from freshmen and sophomores are chosen for research analysis. And then, the result data of questionnaire responses are fed into the computer. Microsoft Excel 2003 is adopted to make an accurate analysis. Research findings are demonstrated in the table as follows: 
TABLE I

INVESTIGATION ON PRAGMATIC COMPETENCE OF SUBJECTS

\begin{tabular}{|c|c|c|c|c|c|c|c|c|}
\hline \multirow[b]{2}{*}{ Items } & \multicolumn{4}{|c|}{ Subjects (Freshmen) } & \multicolumn{4}{|c|}{ Subjects (Sophomores) } \\
\hline & $\begin{array}{l}\text { Number of } \\
\text { Subjects } \\
\text { (Correct } \\
\text { Answers) }\end{array}$ & $\begin{array}{l}\text { Number of } \\
\text { Subjects } \\
\text { (Wrong } \\
\text { Answers) }\end{array}$ & $\begin{array}{l}\text { Pragmatic } \\
\text { Failure } \\
\text { Rate }\end{array}$ & $\begin{array}{l}\text { Average } \\
\text { Failure } \\
\text { Rate }\end{array}$ & $\begin{array}{l}\text { Number of } \\
\text { Subjects } \\
\text { (Correct } \\
\text { Answers) }\end{array}$ & $\begin{array}{l}\text { Number of } \\
\text { Subjects } \\
\text { (Wrong } \\
\text { Answers) }\end{array}$ & $\begin{array}{l}\text { Pragmatic } \\
\text { Failure } \\
\text { Rate }\end{array}$ & $\begin{array}{l}\text { Average } \\
\text { Failure } \\
\text { Rate }\end{array}$ \\
\hline 1 & 26 & 154 & $85.6 \%$ & \multirow{20}{*}{$48.6 \%$} & 25 & 155 & $86.1 \%$ & \multirow{20}{*}{$49.2 \%$} \\
\hline 2 & 131 & 49 & $27.2 \%$ & & 134 & 46 & $25.6 \%$ & \\
\hline 3 & 66 & 114 & $63.3 \%$ & & 64 & 116 & $64.4 \%$ & \\
\hline 4 & 59 & 121 & $67.2 \%$ & & 57 & 123 & $68.3 \%$ & \\
\hline 5 & 101 & 79 & $43.9 \%$ & & 104 & 76 & $42.2 \%$ & \\
\hline 6 & 144 & 36 & $20 \%$ & & 141 & 39 & $21.7 \%$ & \\
\hline 7 & 104 & 76 & $42.2 \%$ & & 100 & 80 & $44.4 \%$ & \\
\hline 8 & 122 & 58 & $32.2 \%$ & & 126 & 56 & $31.1 \%$ & \\
\hline 9 & 130 & 50 & $27.8 \%$ & & 125 & 55 & $30.6 \%$ & \\
\hline 10 & 33 & 147 & $81.7 \%$ & & 37 & 143 & $79.4 \%$ & \\
\hline 11 & 142 & 38 & $21.1 \%$ & & 139 & 41 & $22.7 \%$ & \\
\hline 12 & 91 & 89 & $49.4 \%$ & & 92 & 88 & $48.9 \%$ & \\
\hline 13 & 155 & 25 & $13.9 \%$ & & 145 & 35 & $19.4 \%$ & \\
\hline 14 & 64 & 116 & $64.4 \%$ & & 69 & 111 & $61.7 \%$ & \\
\hline 15 & 119 & 61 & $33.9 \%$ & & 117 & 63 & $35 \%$ & \\
\hline 16 & 42 & 138 & $76.7 \%$ & & 48 & 132 & $73.3 \%$ & \\
\hline 17 & 78 & 102 & $56.7 \%$ & & 73 & 107 & $59.4 \%$ & \\
\hline 18 & 49 & 131 & $72.8 \%$ & & 46 & 134 & $74.4 \%$ & \\
\hline 19 & 107 & 73 & $40.6 \%$ & & 106 & 74 & $41.1 \%$ & \\
\hline 20 & 86 & 94 & $52.2 \%$ & & 84 & 96 & $53.3 \%$ & \\
\hline
\end{tabular}

In 20 items of the questionnaire, the average pragmatic failure rate for freshmen is $48.6 \%$, and that of sophomores is $49.2 \%$, which is 0.6 percent higher than that of freshmen. This clearly shows that those sophomores, who have passed CET-4, are assumed to have a better command of linguistic competence, are inferior to freshmen in pragmatic competence. Thus, it can be concluded that there is no direct relationship between linguistic competence and pragmatic competence, that is to say, a language learner who is proficient in grammatical rules does not necessarily well in pragmatic competence. Even for everyday language spoken by people, for example, "It doesn't matter", "Never mind", "That's all right" which are taught at English beginners' level, some Chinese English learners still can not use them appropriately in reality, which is illustrated by item 1 of questionnaire. The pragmatic failure rate for freshmen and sophomores are respectively $85.6 \%$ and $86.1 \%$.

Also, out of 360 pieces of questionnaire, 90 pieces are randomly sampled in the process of research, which are used to count their average pragmatic correctness rate according to the range of average score of regular quizzes, midterm exams, final exams, as follows:

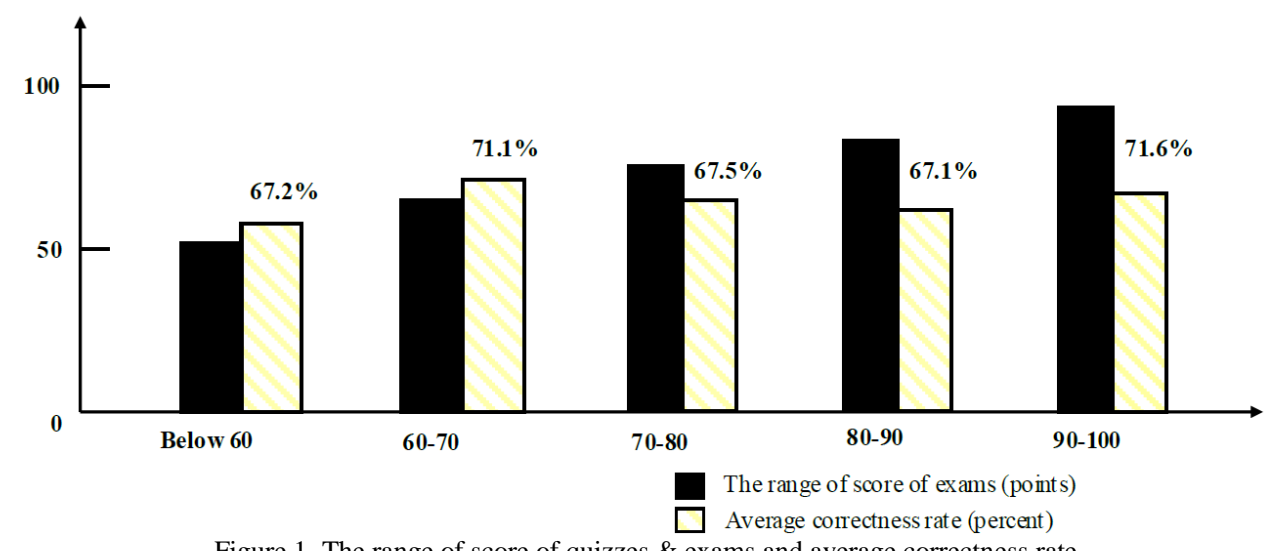

Figure 1. The range of score of quizzes \& exams and average correctness rate

Fig.1 shows us that students with a better command of linguistic competence don't have the advantage in pragmatic competence. Although research findings above are not absolute, it bears out the conclusion that high levels of 
grammatical competence do not guarantee concomitant high levels of pragmatic competence again.

\section{B. Manifestations of Non-English Majors'Pragmatic Failure}

In order to explore the manifestations of non-English majors' pragmatic failure, 140 pieces of questionnaire which are randomly sampled are used to carry out items analysis.

TABLE II

ANALYSIS OF PRAGMATIC FAILURE OF TYPICAL ITEMS

\begin{tabular}{|l|l|l|l|}
\hline Communicative Function & Items & Failure Rate \\
\hline \multirow{4}{*}{ First Part } & rejection & 13 & $4 \%$ \\
\cline { 2 - 4 } & phone calls & 11 & $13 \%$ \\
\hline \multirow{5}{*}{ Second Part } & order & 9 & $21 \%$ \\
\cline { 2 - 4 } & acknowledgement & 2,19 & $33 \%$ \\
\cline { 2 - 4 } & instruction & 6,17 & $36 \%$ \\
\hline \multirow{5}{*}{ Third Part } & expressing concern & 4,15 & $50 \%$ \\
\cline { 2 - 4 } & praise & $8,12,18$ & $52 \%$ \\
\cline { 2 - 4 } & request & $5,7,16,20$ & $55 \%$ \\
\cline { 2 - 4 } & regular usage & 3 & $67 \%$ \\
\cline { 2 - 4 } & greeting & 14 & $69 \%$ \\
\cline { 2 - 4 } & responding to apology & 1,10 & $93 \%$ \\
\hline
\end{tabular}

From Table II we can see that the students perform well in items 13, 11 and 9 with failure rate at $4 \%, 13 \%$ and $21 \%$ respectively. It shows the students, as for refusal, phone calls and order, have got a good command of cross-cultural communication, and can be qualified for communicating with English native speakers. Nevertheless, they are poor at the proper use of regular usage, greetings and responding to apology with failure rate at $67 \%$, 69\% and $93 \%$ respectively. It brings home to us that the students' pragmatic competence should be improved through cultural teaching. Here is a concrete analysis of manifestations of non-English majors' pragmatic failure.

1. Misusing expressions against English idioms

In item 1, one day, when an American lady accidentally bumped into a Chinese young man, she apologized, "I'm terribly sorry". Out of 140 students, 106 for "It doesn't matter", only 10 at correct answer "That's all right". As a matter of fact, students are familiar with four expressions in item 1, but the difficulty comes in how to correctly use in the real situation. Although the choices both "It doesn't matter" and "Never mind" are used to respond to others' apology, they both suggest making others not mind and comforting others. These choices whose correctness rates are not higher are also tested in item 2, 4 and 5 with expressions of acknowledgement, concern, request respectively. Once again, the result demonstrates that students' weakness lies in correct usage of these expressions.

2. Negative transfer because of ignorance in the cultural difference

Native language, as for English learners, has an impact on correct usage of English expressions. The involvement of native language and the influence of native culture can lead to negative transfer. For example, Chinese students hold the idea that they should remain modest when praised, because they are educated on the Chinese cultural background which is different from western culture since childhood. Therefore, in item 8, when it comes to the context Miss Ma is praised, "Your English is quite fluent", 29 \% students make the choice at "Oh, no. Far from that. I still have a long way to go." Another example is just as item 19 shows, Xiao Li as a secretary in the International Computer Engineering Corporation is praised, "Thanks a lot. That's a great help." For this item, 27\% students at the answer, "Oh, it's nothing". Although students answer the questions with strictly observing the principles of modesty and politeness, yet this makes listeners feel suspicious of their own understanding.

3. Inappropriate for the Cooperative Principle (CP)

Famous linguist and language philosopher Grice (1975) proposes the Cooperative Principle (CP) in the article, Logic and Conversation. In Grice's opinion, in all verbal communication, in order to achieve specific aims, there is a tacit understanding between the speaker and hearer, a principle that should be obeyed by speaker and hearer. He called this principle as the Cooperative Principle of conversion. There are four maxims in Cooperative Principle.

(1) The maxim of quantity

a. Make your contribution as informative as is required (for the current purposes of the exchange);

b. Do not make your contribution more informative than is required.

(2) The maxim of quality

Try to make your contribution one that is true, especially:

a. Do not say what you believe to be false;

b. Do not say that for which you lack adequate evidence.

(3) The maxim of relation

Be relevant

(4) The maxim of manner

Be perspicuous, and specifically:

a. Avoid obscurity of expression;

b. Avoid ambiguity; 
c. Be brief (avoid unnecessary prolixity);

d. Be orderly.

If everyone obeys the four maxims strictly, the communication would be the most reasonable and efficient. But in real communication, in order to be polite or something else, the participants often flout the cooperative principle and its maxims.

For example, in item 12, Soon after Mr. Smith's lecture, Li Hua goes on the platform and wants to express the praise for Mr. Smith. 41\% students at the choice, "Dr. Smith, you've made a wonderful lecture". Apparently, it is inappropriate, because in westerners' eyes, academic report should be authentic, which can not be described by the word "wonderful". Also, in item 13, "if someone offers you some food that you really don't like, you might say", obviously, the choice C is not proper for real situation of speaker. As a result, this is against the maxim of quality.

Another example is in item 7, "Xiao Li wanted to ask his advisor, Mr. Smith, to revise his application so he went to his office, entering the room and said", 39 students choose their answer at D: "I am sorry to interrupt you. You see I've never written a letter in English before, so I've probably made lots of problems", which embodies some information beyond requirement, thus it offends against the maxim of quantity.

4. Inappropriate for the Politeness Principle (PP)

The linguist Leech (1983) agrees with the Cooperative Principle (CP) and in his Principles of Pragmatic says that there exists a set of maxims that guide and constrain the conversation of rational people. But he claims that the $\mathrm{CP}$ should be modified because it can not explain very well why people do not often observe the CP. Therefore, he proposes Politeness Principle which makes up for the lack of Cooperative Principle and increases the expression of politeness. He patterns on Grice's CP and divides the PP into six maxims, each of which has two sub-maxims as follows:

(1) Tact maxim (in impositives and commissives)

a. Minimize cost to other

b. Maximize benefit to other

(2) Generosity maxim (in impositives and commissives)

a. Minimize benefit to self

b. Maximize cost to self

(3) Approbation maxim (in expressives and assertives)

a. Minimize dispraise of other

b. Maximize praise of other

(4) Modesty maxim (in expressives and assertives)

a. Minimize praise of self

b. Maximize dispraise of self

(5) Agreement maxim (in assertives)

a. Minimize disagreement between self and other

b. Maximize agreement between self and other

(6) Sympathy maxim (in assertives)

a. Minimize antipathy between self and other

b. Maximize sympathy between self and other

Leech notes that not all the maxims are equally important. Tact maxim appears to be a more powerful constraint on conversational behavior than generosity maxim, while approbation maxim is more important than modesty maxim. And he suggests that "politeness is focused more strongly on other than on self" (Leech, 2003, p.536).

For example, in item 14, "Wei Dong meets his English teacher, Dr Johns, outside the classroom. Wei says", 46 students agrees with the choice "Hi, Dr Johns." But, we know that the words "Hi" and "Hello" are qualified for friends, rather than the elders, thus, this is against Politeness Principle.

However, over-politeness also is not too tactful, as in item 20, sixty-five students' the choice at B "Excuse me, would you mind taking me to the airport?" and C "Would you please take me to the airport?" which accounts for $47 \%$. In fact, it is OK for you to say "Airport, please!" to taxi driver.

\section{Corresponding Suggestions for AVoiding Pragmatic Failure}

According to survey findings and analysis of pragmatic failure, it can be apparently seen that the phenomenon of non-English majors' pragmatic failure is very common. To some extent, much pragmatic failure is more serious than grammar mistakes. Wolfson (1989) points out, in communication with foreigners, they are more lenient towards those mistakes on pronunciation and grammar, while for violation of communicative principles, they will consider it impolite. Language learners must not only acquire the correct forms and sounds of the target language, but also the knowledge of how language is pragmatically used in the target culture (Leech, 1983). Therefore, pragmatic competence seems more important than linguistic competence. The reasons of non-English-major college students' pragmatic failure lie in many facets, such as inappropriate teaching concept, ignorance of pragmatic knowledge, lack of interactive English learning environment, etc. Thus there are some advice for improving English learning and teaching and avoiding pragmatic failure in the following: 


\section{A. Raising English Teachers' and Learners' Intercultural Awareness}

Cross-cultural awareness is the term used to describe sensitivity to the impact of culturally-induced behavior on language use and communication. In order to successfully interact with English native speakers, we have to understand our own and target cultural values, norms, customs and social systems. Teachers should not only teach language knowledge but also the culture connotation and try to integrate the target culture into English teaching, and remind the students of understanding the pattern of thought, social convention, value orientation, life style, history tradition, etc. between China and western countries. Try to provide opportunities for students to know about the English-speaking countries' culture as much as possible, training the comprehensive competence of cross-culture communication. It is practical to make good use of textbooks together with authentic materials such as English film scripts, plays, newspapers, articles and Internet, etc. to provide relevant cultural information so as to widen the students' cultural knowledge. In addition, it is possible to develop their ability to identify areas of possible misunderstanding so as to avoid such miscommunication.

\section{B. Instructing Pragmatic Knowledge as Much as Possible}

Many researches have explored the impact of instruction on pragmatic development in several facets, such as implication (Kubota, 1995), pragmatic fluency (House, 1996). Hymes (1972) points out that grammar rules will be useless if one does not know the applied principles of language. It is well accepted that the ultimate purpose of language learning is for successful communication, which demands both linguistic and pragmatic competence. Kasper (2001) proposes that learners' awareness of appropriate pragmatic behavior can be raised through explicit teaching and meta-pragmatic treatment of pragmatic features by way of description, explanation, and discussion. As a result, English teachers should provide students with explicit teaching on pragmatic knowledge, exposing learners to the pragmatic aspects of language. Also, teachers should create much more opportunities for students to increase their use of pragmatic knowledge. Eslami-Rasekh (2005) suggests that awareness-raising activities, such as what is considered an offence in their culture compared to the target culture and what are different degrees of offence for different situations in the two languages (L1 and L2), are helpful to expose students to the pragmatic aspects of language and provide them with the analytical tools they need to arrive at their own generalizations concerning contextually appropriate language use. Since pragmatic knowledge is as important as linguistic knowledge, teachers should integrate pragmatic knowledge teaching into English teaching.

\section{Creating an Interactive Language Learning Environment}

Definitely, a favorable language learning environment is essential for students to pick up English well. It involves in many aspects. Undoubtedly, in class, it is necessary for English teachers to create a relaxing, interactive environment and offer some opportunities for learners to use the target language rather than one-way learning from the teachers. The teachers should create some situations close to reality, such as how to interview for a job, how to teach as a teacher, how to do business as a boss, etc. Role-play, simulation and drama engage students in different social roles and provide opportunities to practice the wide range of pragmatic and sociolinguistic abilities (Olshtain \& Cohen, 1991). Fostering pragmatic competence relies largely on the practice of pragmatic knowledge in interactive communication. Therefore, we should adopt various kinds of modern teaching media and methods in order to make the students have an immersed sense and learn English naturally. For instance, students should be encouraged to communicate with English native speakers on and off campus, or through the Internet as much as possible, for constant exposure to use of the language. Also, we may introduce some English original movies as much as possible to students and let them contact a large number of real English materials through surfing on the English websites, which help widen students' horizon and intensify the understanding of culture difference between China and English-speaking countries. On the whole, a good language learning environment has greater influence on English learning of the students. Every teacher and every student should realize the crucial role that an interactive language learning environment plays in arousing the students' passion of learning English well.

\section{CONCLUSION}

This paper carries out questionnaire survey on Chinese non-English-major college students, aiming at analyzing the phenomena of pragmatic failure committed by non-English majors in the real communication with native English speakers. After analyzing and generalizing some common manifestations of non-English majors' pragmatic failure, some suggestions for avoiding pragmatic failure and improving English teaching and learning are come up with above. As the core of communicative competence, pragmatic competence is the prerequisite to successful intercultural communication. Since communication is a dynamic process which consists of coding and decoding, it is not possible to convey all pragmatic rules to students, but it is necessary to strengthen students' awareness of those rules by exposing them to authentic English materials and practice in context.

From the survey findings and analysis above, it can be seen that the phenomenon of non-English majors' pragmatic failure is very common. "High levels of grammatical competence do not guarantee concomitant high levels of pragmatic competence" (Bardovi-Harlig, 1999, p.686). We gain the inspiration that only by integrating the pragmatic knowledge and culture teaching into the training of pragmatic competence and linguistic competence and then 
innovating teaching concept, teaching method, teaching content, etc. can we intensify the students' pragmatic consciousness, reduce their pragmatic failure and strengthen their pragmatic competence.

\section{REFERENCES}

[1] Bardovi-Harlig, K. (1999). Exploring the Interlanguage of Interlanguage Pragmatics: A Research Agenda For Acquisitional Pragmatics. Language Learning, 49, 677-713.

[2] Eslami-Rasekh, Z. (2005). Raising the Pragmatic Awareness of Language Learners. ELT Journal, 3, 199-208.

[3] Geoffrey N. Leech. (1983). Principles of Pragmatics. New York: Addison Wesley Longman. Ltd.

[4] Grice, H. P. (1975). Logic and Conversation. In Cole, P \& Morgan, J. (eds.), Syntax and Semantics. New York: Academic Press, 41-58.

[5] Gu Tongqing. (2003). An Overview and Analysis of Non-English-major Masters' English Pragmatic Competence. Journal of Ningbo University (Educational Science), 1, 86-89.

[6] He Zhaoxiong. (2003). Selected Readings for Pragmatics. Shanghai: Shanghai Foreign Language Education Press.

[7] He Ziran. (1988). A Survey of Pragmatics. Changsha: Hunan Education Press.

[8] He Ziran \& Yan Zhuang. (1986). Pragmatic Failures of Chinese Students in Communication in English - An Investigation of Chinese-English Pragmatic Difference. Foreign Language Teaching and Research, 3, 52-57.

[9] Hong Gang. (1991). An Investigation of English Pragmatic Competence and Its Inspiration on Foreign Language Teaching. Foreign Language Teaching and Research, 4, 56-60.

[10] House, J. (1996). Developing Pragmatic Fluency in English as a Foreign Language: Routines and Metapragmatic Awareness. Studies in Second Language Acquisition, 18, 225-252.

[11] Huang Cidong. (1984). Pragmatics and Pragmatic Failure. Journal of Foreign Languages, 1, 13-18.

[12] Hymes, D. H. (1972). On Communicative Competence. In J. Pride \& J. Holmes (eds.), Sociolinguistics. Harmondsworth: Penguin, 269-293.

[13] Kasper, G.. (2001). Four Perspectives on L2 Pragmatic Development. Applied Linguistics, 4, 502-530.

[14] Kubota, M. (1995). Teachability of Conversational Implicature to Japanese EFL Learners. The Institute for Research in Language Teaching Bulletin, 9, 35-67.

[15] Li Huaikui. (2005). Chinese Researchers' Empirical Studies on Learners' FL Pragmatic Competence: Overview and Analysis. Shandong Foreign Language Teaching Journal, 5, 60-63.

[16] Olshtain, E. and Cohen, A.D. (1991). Teaching Speech Act Behavior to Nonnative Speakers. In Celce-Murcia (ed.), Teaching English as a Second and Foreign Language. Boston: Heinle \& Heinle, 167-180.

[17] The Higher Education Dept. of the Ministry of Education of P. R. China. (2007). College English Curriculum Requirements. Shanghai: Shanghai Foreign Language Education Press.

[18] Thomas, J. (1983). Cross-Cultural Pragmatic Failure. Applied Linguistics. 2, 91-122.

[19] Wang Dexing. (1990). Pragmatic Problems in Cross-Cultural Communication. Foreign Language Teaching and Research, 4, 7-11.

[20] Wolfson, N. (1983). Rules of Speaking. In J.C. Richards \& R.W. Schmidt (eds.), Language and Communication. London: Longman, 61-87.

[21] Wolfson, N. (1989). Perspectives: Sociolinguistics and TESOL. Philadelphia: Newbury HouseBub.

Haigang Li was born in Qiqihaer, Heilongjiang province, China in 1977. He received his B.A. degree in linguistics from Jilin University, China in 2003.

He is currently a lecturer in the Department of Foreign Languages, Zhengzhou Institute of Aeronautical Industry Management, Zhengzhou, China. He has completed a number of projects, published more than 8 papers. His research interests include English linguistics and English Teaching. 